\title{
Carnets
}

Revue électronique d'études françaises de l'APEF

Première Série - $1 \mid 2009$

La mer... dans tous ses états

\section{Abordagens interdisciplinares ao 'psychisme hydrant' bachelardiano na poesia de António Gedeão e Jorge de Sena. Uma poética da metamorfose}

\section{Christopher Damien Auretta}

\section{(2) OpenEdition}

\section{Journals}

Edição electrónica

URL: http://journals.openedition.org/carnets/2803

DOI: $10.4000 /$ carnets.2803

ISSN: 1646-7698

Editora

APEF

Edição impressa

Paginação: 33-53

Refêrencia eletrónica

Christopher Damien Auretta, « Abordagens interdisciplinares ao 'psychisme hydrant' bachelardiano na poesia de António Gedeão e Jorge de Sena. Uma poética da metamorfose », Carnets [Online], Première Série - 1 | 2009, posto online no dia 13 junho 2018, consultado o 04 maio 2019. URL : http:// journals.openedition.org/carnets/2803; DOI : 10.4000/carnets.2803

\section{cc) (i) (8)}

Carnets est mis à disposition selon les termes de la licence Creative Commons - Atribution - Pas d'utilisation commerciale 4.0 International. 


\section{ABORDAGENS INTERDISCIPLINARES AO "PSYCHISME HYDRANT" BACHELARDIANO NA POESIA DE ANTÓNIO GEDEÃO E JORGE DE SENA \\ Uma poética da metamorfose}

CHRISTOPHER DAMIEN AURETTA

Universidade Nova de Lisboa

cda@fct.unl.pt

\section{Resumo}

Dois poetas portugueses do século XX, António Gedeão (1906-1997) e Jorge de Sena (1919-1978), encontram-se neste estudo aparentados no que respeita ao tema do mar. Reflectem por sua vez a presença tutelar de duas fontes francesas: o físico e engenheiro Sadi Carnot, autor de um trabalho na área da termodinâmica (1824), cuja teorização pioneira se encontra transposta em lei poética no poema "Lição sobre a água" do poeta António Gedeão; o compositor Claude Debussy, cujo Prelúdio intitulado "La Cathédrale Engloutie" se encontra transposto no poema do mesmo título de Jorge de Sena - texto iniciático em que o poeta se torna consciente de si mesmo como poeta. A obra de Gaston Bachelard, L'eau et les rêves, proporciona uma chave importante para a compreensão da arte poética complexa destes dois autores.

\section{Abstract}

Two twentieth-century Portuguese poets, António Gedeão (1906-1997) and Jorge de Sena (19191978), are here approached with regard to their treatment of the theme of the sea in their respective poetry. Two representative poems are read in the light of two earlier French sources, respectively: the physicist Sadi Carnot's pioneering work in the area of thermodynamics (1824) becomes a metaphorical poetical "law" in Gedeão's "A Lesson on Water"; Debussy's Prelude entitled "La Cathédrale Engloutie" becomes the archetypal image of the poet's initiation into creative selfconsciousness. Gaston Bachelard's L'eau et les rêves provides an understanding of key features of the complex poetics at work in these two major poets.

Palavras-chave: poesia portuguesa moderna, António Gedeão, Jorge de Sena, Gaston Bachelard, interdisciplinaridade

Keywords: Modern Portuguese Poetry, António Gedeão, Jorge de Sena, Gaston Bachelard, Interdisciplinarity 
Os dois poemas que constituem o horizonte interpretativo e o território temático deste estudo, "Lição sobre a água" de António Gedeão, pseudónimo literário do estudioso da História da Ciência e professor de Físico-Química, Rómulo de Carvalho (1906-1997), de quem se devem destacar numerosos estudos sobre as ideias científicas difundidas e operatórias no século das Luzes em Portugal, e "'La Cathédrale Engloutie' de Debussy", poema que inaugura a colectânea Arte de Música (1968) de Jorge de Sena (1919-1978), poeta, ensaísta e historiador da Literatura Portuguesa e Europeia, encerram e encenam, diferenciadamente, um drama de complexa comunicação poética, i.e, um intenso encontro dialéctico entre a matéria pensada e a matéria pensante. O poema de Gedeão exprime a fecundez ontológica da água de que a Ofélia suicidada a boiar no seu rio-leito mortal seria a trágica e inesperada figuração humana ao passo que o poema de Sena, referindo as marinhas transparências sob as quais se vislumbra, submersa, a adormecida Catedral de Ys anteriormente transposta pelo compositor Debussy em "acordes aquáticos", metamorfoseia a conhecida composição musical em nova arquitectura verbal. Os dois poetas veiculam processos de transposição metafórica na sua obra mediante os quais a consciência humana se redimensiona e renova na plenitude expressiva patente no interior da poesia. Para Gedeão e Sena, a criação poética, ora representa a culminação deste acto de redimensionamento ontológico privilegiado, ora é o próprio instrumento com que este acto se concretiza e de que cada poema é a sua expressão mediadora única.

Eis dois poemas onde a água protagoniza processos de reminiscência autobiográfica e consciencialização poética, reflexos da termodinâmica e intertextualidade culta (a tradição literária britânica no caso do poema de Gedeão, a tradição luso-hispânica no caso do poema

\footnotetext{
${ }^{1}$ Transcreve-se na íntegra este poema no Anexo A, incluído no fim deste estudo. Este poema divide-se em três estrofes, com rima e de métrica vária, em que as duas primeiras estrofes apresentam em tom didáctico certos aspectos físico-químicos da água, a seguir às quais uma terceira estrofe, numa abrupta mudança de enfoque, resume e refunde em quatro versos o destino de Ofélia, heroína shakespeariana desafortunada - virgem desflorada e logo abandonada por Hamlet - que perece num rio "com um nenúfar na mão", na leitura de Gedeão. ${ }_{2}^{2}$ Transcreve-se o poema (extenso) de Sena na íntegra no Anexo B, incluído no fim deste estudo. É de reparar a estrutura anaforicamente ascensional deste poema, de seis estrofes, sem rima, de métrica vária, cuja estrutura conceptual-estética segue de modo sugestivo a bem-conhecida ode "A Francisco de Salinas" de fray Luis de León, humanista castelhano quinhentista, de quem Sena era um leitor e estudioso atento. Repare-se no paralelismo patente nas últimas estrofes dos respectivos poemas. O humanista espanhol insta o seu amigo, detentor da cátedra de música na Universidade de Salamanca a continuar a transformar o ruído da Terra - a sua sensorialidade ilusória - em partitura divina: "!O, suene de contino / Salinas, vuestro son em mis oydos, / por quien al bien divino / despiertan los sentidos, / quedando a lo demás adormecidos!" (León, 2000: 100) ao passo que Sena, conhecedor hors-pair da poesia peninsular quinhentista, escreve: "Ó catedral de sons e de água! Ó música / sombria e luminosa! Ó vácua solidão / tranquila!, Ó agonia doce e calculada!" (Sena: 1978, 172). Apesar de o poeta português, criador de alguns dos poemas eróticos mais rudemente sensuais em língua portuguesa, nunca repudiar a dimensão terrena de que a poesia seria a evidência máxima de um "processo testemunhal" ininterrupto durante mais de quatro décadas de actividade poética, defrontamo-nos com uma transfiguração dos sentidos aparentada, um igualmente extático encontro com a música - ponto de partida para uma ascensão ontológica em vertigem perceptiva. Água e som, acordes e catedrais de som unem-se aqui numa metamorfose complexa do ser. Como afirma Sena, no seu posfácio à colectânea Metamorfoses (1963), incluída em Poesia II, juntamente com outras colectâneas publicadas pelo poeta ao longo dos anos sessenta, inclusive Arte de Música, a poesia "pretende ser o lá onde se transforma o mundo, e, portanto, a quem a lê ou ouve, ensina algo de novo, e é pois de qualquer modo didáctica - o certo é que se não descobre aquilo que, mesmo metaforicamente, não foi conceituado" (Sena, 1978: 162).
} 
de Sena); um posicionamento arguto perante a história da cultura ocidental (o ideário iluminista traído pela história ocidental, uma traição captada pelas ironias ferozmente discretas de Gedeão); e a renovação de uma milenar linhagem humanística traída por uma baixeza desumanizante que tudo contamina, uma baixeza anteriormente denunciada por Camões na sua obra épica e lírica (a cuja obra Sena, o poeta e o crítico, dedicou estudos exaustivos). São dois poemas, portanto, caracterizados por uma complexidade cujo interesse para o leitor e estudioso está relacionado com a densidade do seu tecido conceptual e a sofisticação dos seus processos semióticos que, ora assinalam e exacerbam, ora refundem e superam, as discontinuidades vigentes na modernidade literária. Esta modernidade literária encontra-se imbuída de uma consciência histórica da sua própria tecnicidade operatória à revelia das exigências de um prolongar inquestionado da tradição. Sena explicita esta situação no seu posfácio que acompanha a colectânea Arte de Música, assinalando que actualmente estamos

abertos ao passado, a uma escala que os antigos paradoxalmente nunca conheceram, mesmo quando a cultura deles parecia fixa, e decididamente apoiada numa visão "eterna" da tradição. Talvez seja aliás no entendimento disto a chave para entender-se muito mundo moderno: perdido o valor e o sentido da "tradição" como tal, na modalidade horizontal e vertical das sociedades contemporâneas de massa, a historicidade do passado é chamada naturalmente a substituir a actualidade dele, naquele mundo da consciência, em que a cultura faz individualmente as vezes da vivência colectiva que se perdeu (Sena, 1978: 221).

Assim, numa modernidade que torna porosa a consciência histórica à pluralidade dos seus fundamentos, permitindo-lhe um olhar aprofundado da condição humana fora dos moldes ortodoxos de uma tradição ou de um valor "eterno", a água, tal como se lê nos poemas em questão, adquire uma capacidade metamórfica particular. A água, elemento que alimenta os motores e as rêveries surge neste contexto como uma fonte inesgotável de novo sentido. Além disso, a leitura comparada e contrastiva destes dois poemas aprofundou em nós a convicção da pertinência do pensamento de Gaston Bachelard, em particular no que respeita à "imagination formelle" e à "imagination substantielle" (Bachelard, 1942: 7) aplicadas ao elemento da água, elemento fundamental, recorda-nos Bachelard, em numerosas cosmologias desde a Antiguidade, patentes na obra de poetas e filósofos da natureza. Perante o universo simbólico geral deste elemento e a sua manifestação poética em obras específicas, o autor de La formation de l'esprit scientifique traça, na sua psicanálise da "rêverie", uma nítida dicotomia entre uma escrita poética cuja interpretação se pode esgotar na apreciação da sua superfície imagética (onde reina o pitoresco e o fugidio, a metamorfose das formas no seu estádio de máxima labilidade) e uma interpretação, de 
detecção mais problemática, da sua subjacente causalidade material que se alicerça numa doutrina do "psychisme hydrant" - cosmos mortal, nocturno, melancólico, dotado, não obstante, de insólitos poderes metamórficos e germinativos, donde emerge "un lest, une densité, une lenteur, une germination" (Bachelard, 1942: 8).

Tendo como objectivo a exploração da temática do mar na literatura, optámos neste estudo por uma abordagem a uma água metamórfica, nocturna, obscuramente metamorfoseante e estranhamente germinativa. Todavia, no presente estudo, o mar reaparece, ora transformado em vapor propulsionando êmbolos rememorativos das máquinas hidráulicas e fabris que permitiram o desenvolvimento da Revolução Industrial (e que uma miríade de poetas da época tinham já testemunhado e explorado, cientes de que a máquina de vapor era o avatar de uma civilização da Máquina, uma civilização do Novo, uma civilização em que a percepção e a experimentação do tempo e do espaço emergiriam irreversivelmente transfiguradas ${ }^{3}$ ), ora recordado em forma de mares mais de natureza acústica do que de natureza aquática - mares tranfigurados, no caso do poema de Sena, no líquido metaforicamente amniótico de um despertar ontológico, em acto de baptismo do poeta que nasce para e com a palavra. Nele, o nascimento da consciência poética, o seu incipit absoluto, ocorre ao ouvir, ainda adolescente e "jovem tiranizado e triste", aquele mar musicalmente transposto (onde jaz submersa a Catedral de $Y s$ ) do Prelúdio $X$ do Primeiro Livro dos Prelúdios (composto entre 1909-1910, para piano) de Claude Debussy (18621918). De novo, é Bachelard que nos guia nesta inesperada associação do acústico ao aquático, ao afirmar que

les voix de l'eau sont à peine métaphoriques, que le langage des eaux est une réalité poétique directe, que les ruisseaux et les fleuves sonorisent avec une étrange fidélité les paysages muets, que les eaux bruissantes apprennent aux oiseaux et aux hommes à chanter, à parler, à redire, et qu'il y a en somme continuité entre la parole

\footnotetext{
${ }^{3} \mathrm{~V}$. a este respeito a colectânea de ensaios publicada com o título De Prométhée à la machine à vapeur, Cosmogonies et mythes fondateurs à travers le temps et l'espace, organizado por Aline Le Berre. O ensaio "La machine à vapeur, mythe fondateur de la modernité (en France et en Italie à partir de 1830)" de Tommaso Meldolesi é de particular interesse. António Gedeão, ao incorporar na sua "Lição sobre a água" uma alusão às máquinas a vapor, dá continuidade, portanto, a um tema explorado desde há longa data. Gedeão inova este tema precisamente pelo facto de pôr em relevo uma dissonância conceptual que nem glorifica nem vilifica a máquina, como muitos poetas anteriores haviam feito. Não: o conflito dificilmente irresolúvel neste poema reside alhures, i.e., na desconcertante aposição de duas realidades que resistem a todo o nosso esforço de reconciliação. Como, de facto, havemos de reconciliar, numa linguagem comum, i.e., de pressupostos filosóficos e cognitivos comuns, as leis da termodinâmica e as que produzem o pathos trágico? O poema de Gedeão funciona exactamente nesta brecha conceptual, dificilmente franqueada, provocada pelas discontinuidades de uma modernidade cujos especialismos dificultam, ou mesmo visam desqualificar, a comunicação das ideias provenientes dos vários quadrantes da cultura moderna. O poeta português suspende, sem jamais abolir de todo, esta discontinuidade num estado de ironia insolúvel, alargando esta suspensão até absorver aquelas águas melancólicas em que se afoga a malfadada Ofélia, estendida no seu leito mortal, sob um "luar gomoso e branco de camélia". Uma reconciliação, portanto, irrealizável, a menos que se aceite que o poema pode, ele próprio, tornar-se numa espécie de metafórica máquina a vapor, numa ciência ficcional da mecânica do calor, numa termodinâmica transposta.
} 
de l'eau et la parole humaine. Inversement, nous insisterons sur le fait trop peu remarqué qu'organiquement le langage humain a une liquidité, un débit, dans l'ensemble, une eau dans les consonnes (Bachelard, 1942: 24).

\section{“L'eau est le cosmos de la mort”: lições e contra-lições}

No caso da "Lição sobre a água" de Gedeão, repita-se, defrontamos-nos com uma discontinuidade que, hoje em dia, resulta da clivagem patente entre a cultura de raiz filológico-humanística, por um lado, e, por outro, uma cultura largamente influenciada pela evolução da ciência (as ciências empíricas, sobretudo) e da tecnologia desde há vários séculos ${ }^{4}$. Discontinuidade ao nível de práxis simbólica, dicotomia ao nível de vivência cultural e dissídio ao nível de identificação e/ou formação disciplinar tornam problemática a leitura cabal do poema: mais do que uma questão de comunicação poética, portanto, tratase aqui da questão da comunicabilidade, i.e., da possibilidade de poiesis em si a comunicar efectivamente no interior da modernidade técnico-científica. Ver-se-á que a lição que este poema encerra reside na clivagem epistemológica que subjaz a esta experiência de discontinuidade. A lição será múltipla e polivalente, transparente e turva, problemática e elucidativa: o todo suspenso na liquidez metamórfica inerente ao universo temático da água. Gaston Bachelard orientará os nossos passos na interpretação da "Lição". Recorde-se neste contexto a sua afirmação no seu estudo L'eau et les rêves que

l'eau est [...] un type de destin, non plus seulement le vain destin des images fuyantes, le vain destin d'un rêve qui ne s'achève pas, mais un destin essentiel qui métamorphose sans cesse la substance de l'être. Dès lors, le lecteur comprendra [...] que l'être humain a le destin de l'eau qui coule. L'eau est vraiment l'élément transitoire. II est la métamorphose ontologique essentielle entre le feu et la terre. L'être voué à l'eau est un être en vertige. II meurt à chaque minute, sans cesse quelque chose de sa substance s'écoule (Bachelard, 1942: 13).

\footnotetext{
${ }^{4}$ É Jorge de Sena que, no seu prefácio às Poesias Completas de António Gedeão, aborda esta noção de discontinuidade no seio da cultura moderna técnico-científica, imbuída de uma cultura científica e humanística que tensamente se conjugam, assinalando que o poeta explora as anfractuosidades da nossa era de formações especializadas tão insensíveis, a maiora das vezes, às frágeis sínteses possíveis. Gedeão realiza esta tensa conjugação de processos e protocolos de descoberta e significação, muito embora tão-só num processo de ironização muito particular: "uma peculiar formação pessoal que, no ambiente específico do nosso tempo, vai encontrando os meios de elidir a cisão entre a cultura científica e cultura literária, pela própria prática da poesia. É curiosíssimo notar como as vivas contradições implícitas nesta posição se reflectem nas diversas características que fomos relevando. O aumento global da difusão da linguagem científica coincide [...] exactamente com a evolução da "alteridade" expressional, e com a centralidade do fulcro de interesse na correlação do poeta com a realidade. Pela sua formação científica [...], o poeta procura superar e progressivamente o consegue de livro para livro, o impasse cultural do nosso e do seu tempo, que faz a poesia literata perder o contacto com uma realidade político-social que é cada vez mais técnica" (Gedeão, 1964: 26).
} 
Assim, à semelhança do elemento da água, um dos quatro fundamentos elementares abordados por Bachelard nos seus estudos sobre a imaginação "substantielle", esta água inunda com as suas forças metamórficas e metamorfoseantes o leitor tanto como a significação ulterior do poema: o texto constitui uma lição, sim, mas igualmente, e mais complexamente, uma espécie de ciência metafórica. Na violenta aposição da máquina a vapor referida e o corpo flutuante de Ofélia, vislumbra-se uma máquina de vapor que produz, na semiose interna do poema, não apenas força locomotora, de acordo com as leis da termodinâmica mas igualmente ímpeto metafórico. Resumindo: nas entrelinhas de uma ciência hidráulica que o poema comunica, infiltra-se uma hidráulica figurada, prenhe do "destin" sobre o qual escreve o filósofo francês: um destino, veiculado, na terceira estrofe, pela figura de Ofélia, filha de Polónio, irmã de Laertes, amante malfadada do Príncipe Hamlet. Na mudez suicidária de Ofélia, emerge essa ciência de interlúdio de ciência e sombra, de máquinas e metáfora, de termodinâmica e pathos trágico.

O texto de Gedeão desafia por certo a legibilidade do mundo no que respeita ao leitor munido de uma cultura humanística apenas. Com efeito, como se há-de interiorizar a lição que se pretende comunicar quando a superfície denotativa do poema ela própria - ou antes, relembrando as palavras do poeta e crítico anglo-americano T.S. Eliot, o seu correlativo objectivo - pressupõe e simultaneamente impede toda a interpretação literal do poema? Como se há-de entender ulteriormente o núcleo temático dessa lição relativamente às propriedades da água (os seus usos hidrodinâmicos, o seu comportamento em sistemas físicos fechados ou isolados, etc.) que este poema de carácter ostensivamente didáctico parece de início promover? Contudo, quanto mais elucidativo o poema em questão patenteia ser, quanto mais o poema se comporta à laia de um manual de física para uso didáctico, menos transparente, de facto, se torna a liquidez. O correlativo objectivo, i.e., a água que se apresenta nas duas primeiras estrofes do poema na sua natureza sub specie aeternitatis, regida pelas leis imutáveis da física, regida esta por sua vez por uma cosmologia físico-química plenamente matematizável, desemboca, na terceira e última estrofe, num inesperado universo semântico, num território semiótico tanto mais metafórico e qualitativo quanto as duas primeiras estrofes do mesmo poema privilegiam a limpidez das verdades empíricas, a pureza dos comportamentos mensuráveis, a transparência das realidades averiguadas. O leitor, que até ao final da segunda estrofe, se encontra guiado pelas mãos neutras de um transmissor de dados sem nome (característica do tom anónimo do compêndio escolar), está em vias de assimilar de facto apenas o primeiro horizonte interpretativo do poema. Até aqui, o poema é pródigo em certezas: reina, por assim dizer, uma paz epistemológica que não desmente o ambiente laboratorial e/ou pedagógico, lugares que garantem a transmissão das certezas calmas. Esta água é, na suprema literalidade da sua apresentação inicial, uma água não (des)figurada pela ambiguidade, pela 
incerteza ou pelo questionamento filosófico ou conceptual. Dado que toda a "Lição" assenta na práxis de um processo de experimentação e verificação rigoroso - um processo cujos protocolos de descoberta e averiguação pressupõem o afastamento e a neutralização das visões idiossincráticas e das imprevisibilidades da compreensão subjectiva - o poema de Gedeão efectua uma metamorfose de paz epistemológica em desassossego discreto, em desconsolo "viscoso", incontornável, em perplexidade cognitva.

A retórica auxilia-nos a abordar a tensão interna de que o poema é a tradução fina e concretização linguística. A enálage, resultante de uma declinação (em termos de número, género, inflexão verbal, etc.) propositadamente falaz (recorde-se o bem-conhecido verso rimbaldiano: "Je est un autre") encena uma violência sintáctica que visa efeitos amiúde parodísticos ou irónicos. No poema de Gedeão, um caso insólito de enálage emerge, não a nível estritamente sintáctico, mas, sim, a nível conceptual. Como se há-de efectuar a conjugação das máquinas com Ofélia, a reconciliação da teoria da mecânica do calor com o cadáver arrefecido da heroína shakespeariana? Como se há-de resolver, mesmo tenuemente, esta lição, inicialmente transparente, agora radicalmente aporética? Que tem ainda a segredar-nos a água que agora nos inunda?

\section{"[L]e langage humain a une liquidité”: sobre as máquinas a vapor e a água ofélica}

Para fazer frente ao desafio que o poema de Gedeão nos lança, citamos novamente Bachelard: "Pour certains rêveurs, l'eau est le cosmos de la mort. L'ophélisation est alors substantielle. L'eau est nocturne. Près d'elle tout incline à la mort. L'eau communique avec toutes les puissances de la nuit et de la mort (Bachelard, 1942: 106). A lição do poema em questão é, vê-se, simultaneamente lição e exemplo, elucidação objectiva e encarnação verbal do mesmo princípio metamorfoseante da água abordado por Bachelard. Sendo assim, a máquina a vapor referida nas duas primeiras estrofes re-aparecerá, transfigurada, na última: a capacidade ofelizante da água irá reconfigurar a máquina num novo tipo de máquina, desta vez, metafórica: um motor a metáforas pelo qual passa uma água ofélica, melancólica, nocturna. Como assim?

Em 1824, o físico Sadi Carnot publica as suas Réflexions sur la puissance motrice $d u$ feu, uma obra extremamente influente na história da ciência e da tecnologia do século XIX. Nesta obra, o autor debruça-se sobre o funcionamento físico das máquinas a vapor, pois, como afirma Carnot no primeiro parágrafo destas Réflexions: "Personne n'ignore que la chaleur peut être la cause du mouvement, qu'elle possède même une grande puissance motrice: les machines à vapeur, aujourd'hui si répandues, en sont une preuve parlante à tous les yeux" (Carnot, [1824], 1986: 46). Na verdade, é nesta obra que se esboça pela 
primeira vez, embora de modo ainda incompleto e com uma teorização algo equivocada ${ }^{5}$, o aumento da eficiência da máquina a vapor, sendo possível através do designado ciclo de Carnot determinar a fracção de calor disponível que se pode transformar em trabalho. Esta não-convertabilidade integral do calor em trabalho, i.e., de energia calorífica em energia mecânica (o contrário é possível, o trabalho pode transformar-se completamente em calor, por atrito) serviu de base para a formulação do Segundo Princípio da Termodinâmica (princípio empírico), cuja teorização será efectuada independentemente pelo alemão Rudolf Clausius e o britânico Sir William Thomson Kelvin, a partir de 1850, aproveitando-se os dois físicos do trabalho do britânico James Prescott Joule, que descobre a equivalência da energia mecânica e a energia calorífica, e, posteriormente, para a formulação do conceito de entropia. Carnot é, portanto, fulcral para a evolução das ideias que conduziram à formulação do conceito de entropia: num sistema isolado, a entropia cresce sempre numa transformação irreversível, ou seja, só se dão espontaneamente as transformações em que a entropia cresce, entropia que fisicamente se relaciona com a medida de desordem que inevitavelmente se introduz em todos os sistemas físicos não abertos (uma máquina a vapor é, por exemplo, um sistema considerado fechado). O papel desempenhado por Carnot é indispensável para a compreensão da produção de energia mecânica:

La production de la puissance motrice est donc due, dans les machines à vapeur, non à une consummation réelle du calorique, mais à son transport d'un corps chaud à un corps froid, c'est-à-dire à son rétablissement d'équilibre, équilibre supposé rompu par quelque cause que ce soit, par une action chimique, telle que la combustion, ou par toute autre. Nous verrons bientôt que ce principe est applicable à toute machine mise en mouvement par la chaleur (Carnot, [1824], 1986: 52).

\section{A terceira estrofe do poema de Gedeão:}
Foi neste líquido que numa noite cálida de Verão, sob um luar gomoso e branco de camélia, apareceu a boiar o cadáver de Ofélia com um nenúfar na mão (Gedeão, 1996: 62).

comunica, na linguagem transposta da tragédia de raiz shakespeariana, os elementos essenciais com os quais as duas primeiras estrofes formulam parcelar mas implicitamente a

\footnotetext{
${ }^{5}$ Carnot não toma em conta o facto de o calor e o trabalho serem na realidade duas formas de energia. Sem ainda excluir o conceito do calórico, conceito falaz formulado duas gerações antes de Carnot por Lavoisier, que seria, segundo este, um fluído invisível, sem peso, a distinguir da energia de origem mecânica, Carnot não chega a formular uma teorização completa da posteriormente articulada segunda lei da termodinâmica. Com efeito, Carnot não reconhece que é impossível converter integralmente o calor em trabalho. Uma parte da energia perde-se irreversivelmente durante o processo de produção de trabalho.
} 
segunda lei da termodinâmica: o trabalho produzido pelo calor das máqinas a vapor emerge metamorfoseado no corpo ofélico. Especificamente, eis diante de nós, os leitores, um motor cujo invólucro é, por último, um corpo, e cuja fonte de combustão é, em última instância, um coração desejante que se perde em plena solidão nocturna. Com a morte de Ofélia, de facto, a "máquina" da tragédia shakespeariana perde o seu momentum interno, chegando rapidamente ao seu desenlace de desordem máxima: morte de Hamlet, dissolução da dinastia dos Hamlet, morte do usurpador do trono, Cláudio e da sua consorte traidora, Gertrude, mãe de Hamlet, fim da tragédia ela própria como drama dentro de um drama, drama da vida como inescapável representação de si mesma. É o psicanalista André Green que elucida a posição central detida por Ofélia na engrenagem complexa de Hamlet, figuração ofélica indispensável para essa máquina trágica desencadeada pelo dramaturgo inglês:

Ophélie est peut-être le seul caractère humain d'Hamlet, le seul vraiment tragique, parce que déchiré entre la confiance naïve, la pitié pour ceux qu'elle aime et le sentiment de l'irréparable. [...] Apparemment sa mort sera sans conséquence. En fait c'est sa disparition qui est la clé du dénouement. À partir de cet instant Claudius sera déterminé à tuer Hamlet par tous les moyens quand il apprendra que son piège anglais a échoué et que le prince est de retour. Laërte a maintenant deux raisons plutôt qu'une de se venger, en se mettant au service des intérêts de Claudius. Enfin Hamlet lui-même, ayant perdu toute raison d'attacher du prix à sa vie, va se jeter dans la souricière de Claudius (Green, 2003: 176-177).

Green aborda a relação patente entre Ofélia e as flores na tragédia de Shakespeare. Já perto da morte, ela oferece a várias personagens uma flor de espécie específica, cada espécie simbolizando uma virtude ou um defeito, uma condição ou um voto, uma mensagem codificada:

[Ophélie parle] le langage des fleurs. À Laërte elle offre du romarin: souvenir, on s'en sert aux mariages et aux enterrements, et des pensées pour la pensée. Au roi, du fenouil: flatterie; des ancolies: cocuage. À la reine, de la rue: chagrin, et repentir pour Gertrude ainsi que pour elle-même; elles sont unies par un triste sort commun. Voici une pâquerette qu'elle ne donne à personne: dissimulation, parjure des promesses et des serments; sans doute, Ophélie destine-t-elle cette fleur à Hamlet. Enfin, les violettes qu'elle aurait voulu apporter, symbole de fidélité, se sont fanées au moment où son père est mort; encore une allusion probable à la fois à Gertrude et à Hamlet (Green, 2003: 174-175). 
A linguagem das flores permite a Ofélia comunicar sem recorrer à linguagem verbal, doravante degradada pela dissimulação, pela violência e pela traição que se instala no seio da família dos Hamlet. Assim, Ofélia preserva - apesar de moralmente violentada - uma pureza implícita, mais próxima do silêncio do que da palavra, mais próxima das forças germinativas da vida do que da destruição instalada em Elsinore (e portanto ela acaba por representar uma força mais maternal do que libidinosa, mesmo que a sua condição humana no drama traduza uma maternidade cuja progenitura única é a sua própria auto-extinção). Com efeito, sabe-se que a água possui "une profonde maternité" (Bachelard, 1942: 22). É Ofélia a personagem do drama cujo destino, na sua totalidade, corresponde integralmente ao "psychisme hydrant" já referido:

L'eau est l'élément de la mort jeune et belle, de la mort fleurie, et, dans les drames de la vie et de la littérature, elle est l'élément de la mort sans orgueil ni vengeance, du suicide masochiste. [...] C'est l'eau rêvée dans sa vie habituelle, c'est l'eau de l'étang qui d'elle-même "s'ophélise", qui se couvre naturellement d'êtres dormants, d'êtres qui s'abandonnent et qui flottent, d'êtres qui meurent doucement (Bachelard, 1942: 98).

Com efeito, com a morte de Ofélia, o poema-motor pára à míngua de nova combustão; todo o calor se dissipa em parte no "trabalho" fatal que organiza e liberta a tragédia, em parte no arrefecimento do seu corpo que se abandona à noite - cuja única luz, desprovido de calor, provém da Lua, i.e., de um Sol falso, como Hamlet é tão-só o simulacro de um filho, marido e príncipe - e, ulteriormente, à sua entrópica desordem final. "Ofélia"motor, "Ofélia"-coração, "Ofélia"-entropia: o poeta Gedeão cria um texto cujos significados se multiplicam e entrecruzam numa linguagem de enálage conceptual cuja única ponte cognitiva se erige na nostalgia de uma palavra total (audível apenas nas entrelinhas de uma água que tudo devora, tudo afoga, tudo destrói). Gedeão exprime assim, nesta discreta alegoria de incomunicabilidade moderna, a busca de uma linguagem comum e totalizadora. Resta-nos a mudez nocturna de Ofélia.

A lição poética de Gedeão que elide, sem solucionar, a cisão existente entre a cultura técnico-científica e a cultura humanística, por via da insólita aposição de máquinas a vapor e alusões à tragédia shakespeariana, culmina na imagem de um corpo emudecido. Mais do que emudecido: a mudez ontológica de uma água "ofelizada". O poeta comunica assim um estado de profunda incomunicabilidade, i.e., o silêncio que irreversivelmente se instala no reino da água ofélica onde o cosmos, ora se regenera, ora degenera em desamparada alienação. Além disso, este processo de "ofelização" patente no poema recorda uma longa linhagem de heroínas literárias cujos destinos se têm pautado pela imposição de um silêncio complexamente codificado. Ei-las assim simbolizando a água 
estagnada dos destinos truncados, o universo emudecido da condição feminina na sua dimensão trágica, a palavra retornada ao estado de caótica liquidez pré-linguistica. Assim, Ofélia desempenha o papel da palavra em fase crepuscular: a heroína, metafórica encarnação da desordem entrópica, bem como figuração trágica da condição feminina, submete-se a uma codificação comportamental estrita. Quais eram as opções efectivamente ao alcance de Ofélia no drama de Shakespeare?

Esta codificação comportamental enraiza-se na literatura ocidental, encontrando-se já operatória na tragédia grega. A título de exemplo, a especialista de literatura clássica, Nicole Loraux, no seu estudo Façons tragiques de tuer une femme, abordando este tema do silêncio feminino na história da tragédia, afirma que

[l]a gloire (kléos) des hommes est parole vive, portée aux oreilles de la postérité par les mille voix de la renomée; pour dire la gloire d'une femme, il n'est, depuis Pénélope affirmant que seul le retour d'Ulysse fera grandir son kléos amoindri (Odyssée, XIX, 124-128), d'autre orateur que le mari. Celui-lá même qui, par-delà la mort de son épouse, sera le dépositaire de sa mémoire. Le mari une fois mort, aux femmes il reste à ne pas faire parler d'elles parmi les mâles, ni sur le ton du blâme ni sur celui de l'éloge: la gloire des femmes est de n'en pas avoir (Loraux, 1985: 26-27).

Assim, a Ofélia da lição proferida pelo poeta Gedeão é plural e complexa: reúne várias linhas e linhagens de rigorosa codificação estética, simbolização "hydrante" e mesmo, como já se viu, metaforização de processos físicos impossíveis de serem transmitidos (i.e., com rigor matemático) sem ser de modo translato. Mas este "glissement" semântico efectuado pelo poeta na sua "Lição" é prova da comunicação ainda possível entre mares e metodologias ostensivamente estanques. O sacrifício que Ofélia faz de si própria no fim da tragédia de Shakespeare, e, implicitamente, no final do poema de Gedeão, exprime, de acordo com a nossa interpretação, o processo entrópico inerente não apenas aos processos físicos em sistemas fechados mas igualmente no interior de todo o acto comunicativo, i.e., nesses êmbolos metafóricos inscritos num coração que sofre. O ser humano é um mar incurável: dotado de uma liquidez falante, o ser humano naufraga na sua própria fluência deletéria.

Por último, para além de o seu silêncio prolongar uma tradição literária milenar, bem como explorar a interpenetração das culturas científica e literária, vigentes na modernidade ocidental, em insólitas aposições e infiltrações metafóricas, Ofélia concentra no seu pathos todo o universo da água conceptualizado por Bachelard. Sendo o seu destino o de se submeter irremediavelmente a um processo de dissolução dentro de águas mortíferas, o seu retorno ao caos elementar completa a lição de Gedeão. Simbolizando uma liquidez 
dissonante e corrosiva, Ofélia instaura e impõe um reino lunar. Assim, o poeta António Gedeão escolhe a cosmologia da água de modo a exprimir uma semiose de desconsolo e desamparo: apanágio de todos os mares que revelam a condição humana no instante dos seus múltiplos naufrágios.

\section{"[U]ne philosophie concrète, une philosophie totale": acerca da poética seniana}

A água "ofélica" que culmina a "Lição sobre a água" de Gedeão comunica, de acordo com a conceptualização de Bachelard relativamente às "rêveries" da água, a inesperada proximidade entre a sonoridade natural das "paysages muets" e a voz humana plenamente articulada, um parentesco insuspeitado aproximando o elemento da água na sua materialidade profunda às primícias de uma articulada linguagem humana, o reverberar quase vozeado da água cuja prenhez acústica se pode transformar em súbita revelação semiótica e encadeamento sintáctico. Por vezes, tais encadeamentos libertam uma linguagem poética, sendo a poesia, de acordo com Sena,

um acto de apreensão estética [...]. E acontece que o homem - se pode viver e criar abstracções - é pelo rosto e pelos seus gestos, e pelo que ele com o olhar transfigura, que podemos, interrogativamente, incertamente, inquietantemente, angustiadamente, conhecer-lhe a vida. E, se não fora a poesia olhando a História, nenhuma vida em verdade conheceríamos, nem a nossa própria. Não adianta muito, concordarei, este saber, e é mais do que prudente recusá-lo. Mas são precisamente as "metamorfoses" o que nos permite olhar a cabeça de Medusa (Sena, 1978: 163).

Eis uma consciência poética que se estrutura como dialéctico encontro com toda a alteridade que nele reside ou que o permeia, de forma, ora alienada e distante, ora íntima e susceptível de decifração: o todo numa união tensa e para sempre inacabada. Uma consciência poética, portanto, que, submersa nas mesmas águas onde jaz, adormecida, a "cathédrale engloutie", efectua um acto ininterrupto de apreensão (de que a poesia é a máxima concretização linguística possível). Uma consciência poética altamente especulativa que se exprime, de modo agónico (mesmo quando esta apreensão agónica parece manifestar uma serenidade conquistada): um ser, que, olhando "a cabeça de Medusa" da história e da condição humanas, consegue diferir o naufrágio, por nunca perder de vista o que considera ser uma das exigências internas da poesia ela própria: "uma meditação moral [...] que o não é (ou não deve sê-lo) num sentido normativo, mas indubitavelmente o é num sentido escatológico, de inquirição aflita sobre as origens e os fins últimos do Homem" 
(Sena, 1978: 162). A "Medusa" irá, de acordo com o fatalismo intrínseco nos mitos, acabar por levar cada qual ao seu singular e irreversível naufrágio. Porém, até lá, a consciência poética, testemunha da humanidade histórica que a poesia apreende nas simultâneas idealidade e concretização de que é objecto de meditação, questiona o dado, refunde o que poderia parecer uma verdade assente, transformando o real num processo de remodelação dialéctico infindo ${ }^{6}$. A história não é, para Sena, um objecto de revisionismos oportunistas, mas, sim, uma construção reflectida. De modo a caracterizarmos melhor este complexo posicionamento perfilado por Sena relativamente ao processo de consciencialização histórica, refere-se aqui o pensamento de Benjamin, em particular como se pode ler no seguinte trecho das suas Teses sobre a Filosofia da História:

Ao historicismo falta o arcaboiço teórico. O seu modo de proceder é aditivo; ele utiliza a massa de factos para encher o tempo homogéneo e vazio. Pelo contrário, a historiografia materialista repousa num princípio construtivo. Ao pensamento não pertence o movimento das ideias mas também o seu repouso. Quando o pensamento se fixa de repente numa configuração saturada de tensões, comunica-lhe um choque que a cristaliza em mónada. O defensor do materialismo histórico só se aproxima de um objecto histórico quando essa objecto se the apresenta como uma mónada. Nessa estrutura, ele reconhece o sinal de uma passagem messiânica do devir, dito de outro modo uma oportunidade revolucionária no combate pelo passado oprimido (Benjamin, 1992: 168).

$\mathrm{Na}$ poética seniana, conceptualmente complexa, não se testemunha nenhum naufrágio "ofélico" sem que se vislumbre também, no instante da apreensão poética, a negatividade libertadora de novos horizontes de revelação e actuação. Assim, o poema em questão encena a transfiguração de uma história individual, ou antes, de uma biografia familiar, que a audição do Prelúdio $X$ de Debussy intercepta e transfigura: a apreensão poética dissolve as primeiras linhagens - biográficas - a fim de implantar uma nova linhagem de identidade literária, à qual o poeta vota uma fidelidade inquebrantável (recordem-se neste contexto os "quarenta anos de servidão" com que Sena coroa, já em vésperas da sua morte, a sua fidelidade a uma intensa actividade poética de quatro décadas). O poeta abandona, por conseguinte, a visão escatológica menor dos destinos impostos em favor da visão escatológica dum destino maior: aquele longínquo evento de transfiguração que permitiu que, de "sob ou sobre as águas", um "jovem tiranizado e triste" (ao modo da catedral submersa) renascesse em nova consciência poética ascendente.

\footnotetext{
${ }^{6} \mathrm{Na}$ poética seniana, de que o poema em questão é um exemplo subtil, o real pensar-se-ia como idealidade que a poesia concretiza; o pensar seria uma abstracção que o real torna iminente.
} 


\section{“L’eau est un type de destin”: uma lição sob a água de Jorge de Sena}

Se a água, que no pensamento de Bachelard diferencia e fundamenta epistemologicamente uma "connaissance objective" e uma "connaissance imagée" (Bachelard, 1942: 14), representa um instrumento expressivo natural, a consciência humana pode igualmente organizar-se em "acordes aquáticos", acordes portadores para o poeta enquanto jovem iniciado - no instante da "apreensão estética" do Prelúdio $X$ - de uma experiência de extática "agonia doce e calculada". Embora tão-só prelúdio pianístico, num primeiro tempo, a audição, por parte do jovem poeta ainda por nascer, desta composição musical, prenuncia um destino revolucionado: uma nova consciência alargada para todo o sempre incomensurável com a sua biografia anterior, traçada e imposta esta pelas expectativas e exigências, tiranias e mesquinhezes dos outros, "por sob ou sobre as águas, / de negros sóis e brancos céus nocturnos". O poema não refere esta biografia anterior para concomitantemente a repudiar, mas, sim, faz do poema o seu próprio princípio transfigurador. Se, por um lado, Ofélia naufraga irreversivelmente na sua biografia líquida envenenada - flor negra de uma fatídica linhagem literária - que a intertextualidade do poema de Gedeão vem novamente confirmar, o poema de Sena, por outro lado, faz da água um elemento essencialmente instaurador, "baptismal", mais do que fatalmente crepuscular. Ou antes, o poema de Sena integra, numa mesma poética da metamorfose, os elementos germinativos e deletérios associados à água numa mesma inquietação dialéctica, numa mesma negatividade libertadora ${ }^{7}$. Por certo, a água, no poema “'La Cathédrale Engloutie' de Debussy" exprime não a morte das ninfas de linhagem ofélica mas, antes, a vida nova de uma consciência transfigurada pela experiência estética. Sena escreve de facto a respeito desta faculdade de metamorfosear o dado, no seu posfácio à Arte de Música que

[a] música é, como nenhuma outra arte em tão elevado grau, a sua mesma técnica. $\mathrm{E}$ é essa condição de ser uma técnica refinada, que não serve para coisa nenhuma que não seja a criação de si mesma, o que a eleva acima de tudo e de nós mesmos [...]. A meditação desta situação peculiar da música, uma vez que se processe em nível superior e mais íntimo que o mero, ainda que culto, anotar de impressões de ouvi-la,

\footnotetext{
${ }^{7}$ No prefácio que Jorge de Sena escreve aquando da publicação da Poesia l, lê-se a respeito desta negatividade libertadora: "Apesar da minha formação hegeliana e marxista, ou também por causa dela, os contrários são para mim mais complexos do que a aceitação oportunista de maniqueísmos simplistas" (Sena, 1977: 20). Ora, esta vertente hegeliana no pensamento lírico-especulativo de Sena constitui um elemento central na poesia do autor. Relembramos o essencial do conceito de negatividade no pensamento de Hegel mediante a síntese dada por Manuel Antunes: "A negatividade: Constitui-se, radicalmente, como liberdade, isto é, como o poder, que habita o homem, de se separar, de se erguer autónomo, de enfrentar e de tomar consciência da Natureza, do dado ou elemento empírico, do outro, da comunidade, do destino, criando Cultura (Bildung), actividade intelectual do espírito, actividade produtora de um resultado que, na intenção do filósofo Hegel, deve constituir a união, indissolúvel, do abstracto e do concreto, do inteligível e do sensível, do singular da vida e da conjuntura histórica com o universal do pensamento" (Antunes, 2002: 45).
} 
tenderá necessariamente à transfiguração poética (Sena, 1978: 220).

Assim, a poética seniana é uma poética complexa que torna interno um princípio dialéctico radical em virtude do qual, no caso deste poema, a água é sempre mais e menos do que ostensivamente significa. O poema avizinha-se de uma daquelas "paragens messiânicas" invocadas por Benjamin: a água que é inicialmente a imagem de uma identidade "submersa", i.e., alienada das suas virtualidades, transforma-se numa água portadora de uma inesperada redenção terrenal, i.e., a transformação da história humana num devir libertador, rememorativo da filosofia hegeliano-marxista invocada por Sena.

Como último contributo para uma dilucidação da presença do tema do mar nestes dois poetas portugueses (tratando-se, no caso do poema da autoria de António Gedeão, de uma imagem do mar convertido em energia mecânica e calórica, e, no caso do poema de Jorge de Sena, de uma imagem do mar convertido em elemento metamórfico por excelência a guiar uma consciência histórico-poética complexa), achamos pertinente fazer-se uma referência a um dos poemas filosóficos mais importantes do mundo greco-latino. Na obra $D e$ rerum natura de Lucrécio, questões de cosmologia e vida humana perspectivam-se numa mesma meditação filosófica. A filosofia materialista do autor, que estrutura toda a obra, reflecte a sua posição de discípulo atento aos seus mestres, Epicuro e Demócrito, fundadores da primeira teorização atomista do universo. O que tem a ver esta obra com o tema do mar que neste estudo procuramos explorar, se não as próprias palavras do poeta com que afirma conseguir contemplar "la mer immense", "la calme surface des flots", mar face ao qual o poeta consegue olhar desde "les hautes citadelles de la sérénité édifiées par la doctrine des sages" (Lucrèce, 1995: 61)? Além disso, desenvolvendo a sua apresentação da teoria atomista ao seu discípulo Memmius, o poeta revela que um entendimento cabal do universo - um entendimento liberto do terror que provoca a mera ideia da morte juntamente com a panóplia de ilusões que geram os medos, a ignorância e a confusão dos sentimentos na maioria dos seres humanos - promove um estado de benfazeja serenidade no indivíduo correctamente orientado pelos mestres atomistas. Ao contemplar as leis do universo físico (onde operam, recorda-se, conceitos como os de vazio, inércia, átomo, infinito e movimento), o indivíduo atinge uma nova compreensão da sua condição no seio de um universo sem deuses (i.e., sem os irracionalismos egocêntricos e caprichosos dos Titãs e Olímpicos). Pelo contrário, a contemplação destas leis no universo educam uma inteligência e serenam o coração - encerram toda uma moral. Focando especificamente o ciclo de criação e destruição repetido ad infinitum pela acção e interacção dos átomos, Lucrécio escreve:

C'est pourquoi les mouvements destructeurs ne peuvent éternellement l'emporter, ni 
ensevelir toute vie pour l'éternité; pourquoi aussi les mouvements qui assurent la création et la croissance des choses et des êtres ne peuvent assurer à ces créations une vie éternelle: ainsi le combat - guerre engagée depuis l'infini des temps - est-il à égalité entre les principes. Tour à tour, ici ou là, les forces vitales connaissent victoires et défaites: aux gémissements du deuil se mêle le vagissement du bébé qui aborde aux rives de la lumière; et nulle nuit jamais n'a succédée au jour, nulle aurore n'a relevé la nuit sans qu'elles n'aient entendu, mêlées aux vagissements plaintifs du petit enfant, les lugubres lamentations, compagnes de la mort et des noires funérailles (Lucrèce, 1995: 79).

É neste mesmo Livro II dedicado à elucidação da natureza das coisas que Lucrécio introduz o conceito fundamental do clínamen (desvio) que faz com que os átomos, que se movem todos como as "gotas de chuva" ("imbris uti guttae", no original), avancem

dans cette chute en ligne droite qui les entraîne vers le bas, à travers le vide, en fonction de leur poids propre, [...] sans exception, [et] s'écartent tous quelque peu de leur direction, à des moments et en des lieux indéterminés - juste assez pour qu'on puisse parler d'un changement de direction (Lucrèce, 1995: 68).

Pressupõe-se a existência deste pequeno desvio, ou clínamen, i.e., uma ínfima obliquidade - invisível a olho nu -, comportamento atómico essencial na teorização atomista, a fim de poder explicar a criação da ordem universal, pois sem este ínfimo desvio, os átomos iriam seguir eternamente um movimento de estrito paralelismo uns em relação aos outros. Perante o mundo criado, infere-se o que não é directamente observável: o clínamen, sendo a expressão física de um desvio no seio do universo regido por leis inalteráveis, deixa entrever, nesta mesma literalidade de uma mecânica que tudo engloba, uma "excepção". E esta excepção visa nada mais nada menos do que "rompre les lois du destin" (Lucrèce, 1995: 69). É este clínamen que, rompendo o estrito paralelismo em que os átomos se encontravam originalmente, possibilita que o mundo se constitua em turbulência criadora: lá, "aux rives de la lumière c'est une vivante descendance" (Lucrèce, 1995: 81), que se detecta na sua "danse désordonnée de ces grains de poussière dans le soleil: car ces turbulences témoignent de l'animation sous-jacente de la matière, mouvements clandestins et invisibles" (Lucrèce, 1995: 65). Nesta dança da matéria, proporcionada pelo clínamen, "ces poussières, bousculées par d'imperceptibles chocs, infléchi[ssent] leur direction et, repoussées en arrière, rebrouss[ent] chemin - tantôt ici, tantôt là - dans toutes les directions: marche erratique qui ne peut avoir que les atomes pour origine" (Lucrèce, 1995: 65), subjazem a, e criam, o mundo-palco da vida vasta e vária que nos rodeia.

Eis a visão do mundo transmitida por Lucrécio - o "suavi mare magno turbantibus 
aequora ventis" ("o sereno mar infindo visitado pela turbulência da água e do vento"). Remete-nos para o poema de Sena, pois não regista este texto uma turbulência aparentada ao mar de átomos em perpétuo movimento? Michel Serres, no seu estudo da obra de Lucrécio, foca esta natureza turbulenta:

Soit donc l'écoulement, on l'appellera un écoulement laminaire. Cela signifie qu'aussi petites que soient les lames découpées dans le flux, le mouvement de chacune est strictement parallèle au mouvement d'une autre. Ce modèle est fidèle à la description du De natura rerum. Lesdites lamelles en sont les éléments. Ceux-ci sont des solides mais la cataracte est fluide. Or un écoulement laminaire est idéal et comme théorique. Dans l'expérience, il est très rare que tous les flux locaux demeurent parallèles, ils deviennent toujours plus ou moins turbulents (Serres, 1977: 12).

Eis o caminho que se poderá traçar entre a obra de Lucrécio e o poema de Sena: uma afinidade favorável às turbulências, uma ruptura de todo o paralelismo (o destino das genealogias familiares que não admitem o clínamen de uma auto-consciência autónoma), a germinação de todas as formas de que o universo é o recipiente ulterior, no seu cíclico retornar a, e surgir do, nada. Neste germinar universal de que o poema de Sena é testemunho e expressão, o mar é "magno", metamórfico e infinito. O mar, de que longinquamente se ouvem os acordes submersos, no Prelúdio de Debussy, e na transposição poética de Sena, encerra a derradeira alegoria moderna a assinalar neste estudo: a vida comporta uma medida de magnitude renovável, em movimento perpétuo e sujeita às dimensões, ora traídas, ora despertadas, da consciência humana.

O mar é uma linguagem total; o mar é o ar que a palavra respira. 


\section{Bibliografia}

ANTUnES, Manuel (2002). Teoria da Cultura. Maria Ivone de Ornellas de Andrade (org.). Lisboa: Edições Colibri.

BACHELARD, Gaston (1942). L'eau et les rêves. Essai sur l'imagination de la matière. Paris: Librairie José Corti.

Benjamin, Walter (1992). Sobre Arte, Técnica, Linguagem e Política. Lisboa: Relógio D’Água.

CARNOT, Sadi (1842). Réflexions sur la puissance motrice du feu. In: Jean-Marie Maury (ed.). Carnot et la Machine à Vapeur (1986). Paris: Presses Universitaires de France.

GEDEÃO, António (1996). Poemas Escolhidos. Lisboa: Edições João da Costa.

GREEN, André (2003). Hamlet et Hamlet. Une interprétation psychanalytique de la représentation. Paris: Bayard.

LEON, fray Luis de (2000). Poesias Completas. Cristóbal Cuevas (ed.). Madrid: Editorial Castalia.

LORAX, Nicole (1985). Façons tragiques de tuer une femme. Hachette.

LUCRECE (1995). La nature des choses, ed. e trad. Chantal Labry. Arléa.

MELDOLESI, Tommaso (2004). "La machine à vapeur, mythe fondateur de la modernité (en France et en Italie à partir de 1830)". In: Aline Le Berre (org.). De Prométhée à la machine à vapeur. Cosmogonies et mythes fondateurs à travers le temps et l'espace. Limoges: Presses Universitaires de Limoges, pp. 213-230.

SenA, Jorge de (1964). "Prefácio". In: António Gedeão. Poesias Completas (1956-1967). Lisboa: Portugália Editora.

SENA, Jorge de (1977). Poesia-I. Lisboa: Moraes Editores.

SENA, Jorge de (1978). Poesia-II. Lisboa: Moraes Editores.

SERRES, Michel (1977). La naissance de la physique dans le texte de Lucrèce. Paris: Les Éditions de Minuit. 


\section{Anexo I: "Lição sobre a água"}

Este líquido é água.

Quando pura

é inodora, insípida e incolor.

Reduzida a vapor,

sob tensão e a alta temperatura,

move os êmbolos das máquinas que, por isso,

se denominam máquinas de vapor.

É um bom dissolvente.

Embora com excepções mas de um modo geral, dissolve tudo bem, ácidos, bases e sais.

Congela a zero graus centesimais

e ferve a 100, quando à pressão normal.

Foi neste líquido que numa noite cálida de Verão, sob um luar gomoso e branco de camélia, apareceu a boiar o cadáver de Ofélia com um nenúfar na mão.

(Gedeão, 1996: 62) 


\section{Anexo II: “'La Cathédrale Engloutie’ de Debussy”}

Creio que nunca perdoarei o que me fez esta música.

Eu nada sabia de poesia, de literatura, e o piano

era, para mim, sem distinção entre a Viúva Alegre e Mozart,

o grande futuro paralelo a tudo o que eu seria

para satisfação dos meus parentes todos. Mesmo a Música,

eles achavam-na demais, imprópria de um rapaz

que era pretendido igual a todos eles: alto ou baixo funcionário público,

civil ou militar. Eu lia muito, é certo. Lera

o Ponson du Terrail, o Campos Júnior, o Verne e o Salgari,

e o Eça e o Pascoaes. E lera também

nuns caderninhos que me eram permitidos porque aprefeiçoavam o francês,

e a Livraria Larousse editava para crianças mais novas do que eu era,

a história da catedral de Ys submersa nas águas.

Um dia, no rádio Pilot da minha Avó, ouvi

uma série de acordes aquáticos, que os pedais faziam pensativos,

mas cujas dissonâncias eram a imagem tremulante

daquelas fendas ténues que na vida,

na minha e na dos outros, ou havia ou faltavam.

Foi como se as águas se me abrissem para ouvir os sinos,

os cânticos, e o eco das abóbadas, e ver as altas torres

sobre que as ondas glaucas se espumavam tranquilas.

Nas naves povoadas de limos e de anémonas, vi que perpassavam

almas penadas como as do Marão e que eu temia

em todos os estalidos e cantos escuros da casa.

Ante um caderno, tentei dizer tudo isso. Mas

só a música que comprei e estudei ao piano mo ensinou

mas sem palavras. Escrevi. Como o vaso da China

pomposo e com dragões em relevo, que havia na sala,

e que uma criada ao espanejar partiu,

e dele saíram lixo e papéis velhos lá caídos,

as fissuras da vida abriram-se-me para sempre,

ainda que o sentido de muitas eu só entendesse mais tarde.

Submersa catedral inacessível! Como perdoarei

aquele momento em que do rádio vieste,

solene e vaga e grave, de sob as águas que 
marinhas me seriam meu destino perdido?

É desta imprecisão que eu tenho ódio:

nunca mais pude ser eu mesmo - esse homem parvo

que, nascido do jovem tiranizado e triste,

viveria tranquilamente arreliado até à morte.

Passei a ser esta soma teimosa do que não existe:

exigência, anseio, dúvida, e gosto

de impor aos outros a visão profunda,

não a visão que eles fingem,

mas a visão que recusam:

esse lixo do mundo e papéis velhos

que sai dum jarrão exótico que a criada partiu,

como a catedral se iria em acordes que ficam

na memória das coisas como um livro infantil

de lendas de outras terras que não são a minha.

Os acordes perpassam cristalinos sob um fundo surdo,

que docemente ecoa. Música literata e fascinante,

nojento do que por ela em mim se fez poesia,

esta desgraça impotente de actuar no mundo,

e que só sabe negar-se e constranger-me a ser

o que luta no vácuo de si mesmo e dos outros.

Ó catedral de sons e de água! Ó música

sombria e luminosa! Ó vácua solidão

tranquila! Ó agonia doce e calculada!

Ah como havia em ti, tão só prelúdio,

tamanho alvorecer, por sob ou sobre as águas,

de negros sóis e brancos céus nocturnos?

Eu hei-de perdoar-te? Eu hei-de ouvir-te ainda?

Mais uma vez eu te ouço, ou tu, perdão, me escutas?

(Sena, 1978: 171-172) 